\title{
Academic Grants and Contracts Administration
}

National Cancer Institute

\section{Source}

National Cancer Institute. Academic Grants and Contracts Administration. NCI

Thesaurus. Code C18614.

Oversight and management of grants or contracts 